\title{
Rare horizontal fissure in Left Lung and incomplete horizontal fissure in Right Lung: a Case Report
}

\author{
Dr. Padmaja Vasi M.B.B.S., M.D. \\ (Assistant Professor in Anatomy, Gandhi Medical College, Secunderabad - 500 025, Andhra Pradesh, India)
}

\begin{abstract}
Generally, Left Lung is divided into two lobes by a deep oblique fissure and right lung is divided into three lobes by oblique and horizontal fissures. But in our case study during the routine undergraduate dissection of the Thoracic region of a sixty five year old male cadaver in the department of Anatomy, Gandhi Medical College, it was incidentally observed that the left lung is divided into three lobes by oblique and horizontal fissures and incomplete horizontal fissure in the right lung. This type of variation is observed only once in our routine dissection in Anatomy Department and hence presented for its clinical importance.

Keywords - Horizontal Fissure in Left Lung, incomplete horizontal fissure in Right Lung, variation of Fissures in Lungs
\end{abstract}

Submitted date 24 June 2013

Accepted Date: 29 June 2013

\section{INTRODUCTION}

Lungs are the essential organs for respiration; contain large quantity of elastic tissue which permits the expansion of all parts of the lungs on inspiration. The elastic tissue drawing the lung inwards towards its root is the main factor in expiration. Each lung is divided into lobes by fissures. Left lung is divided into two lobes by oblique fissure. Oblique fissure begins posteriorly at the level of fifth thoracic vertebra. It passes anteroinferiorly in a spiral course to meet the inferior margin close to the sixth costochondral junction. It extends into the lung almost to the hilum and separates the inferior and superior lobes. After death the lung collapses to variable degree and diaphragm rises. Thus the upper end of the oblique fissure is often at the level of third thoracic vertebra in the cadaver. Right lung is divided by oblique fissure and this fissure separates the superior and middle lobes from the inferior lobe. A second horizontal fissure extends from anterior margin at fourth costal cartilage horizontally backwards to meet the oblique fissure in the mid axillary line. This separates the wedge middle lobe from the superior lobe. Pulmonary pleura extends into the fissures of the lungs so that the lobes of the lungs can move on each other during respiration. Fissures may be obliterated by inflammation of the pleura (pleurisy) and infection may become localized in the fissure to form an abscess between lobes of the lung. In both cases the pleura in the fissure is thickened and may be visible in the radiographs [1]. Horizontal fissure is present in only in right lung. It is visible in $60 \%$ of cases in PA view of X-ray chest. Oblique fissure is visible in lateral view of chest X-ray. A Left horizontal fissure is normal variant found in $10 \%$ of individuals [2].

\section{CASE REPORT}

During the routine dissection of thorax region for under graduates, it was incidentally observed that the left lung had two fissures i.e., oblique and horizontal fissures dividing the lung into three lobes. Oblique fissure is running obliquely downwards and forwards crossing he posterior border about 2" below the apex and inferior border about 3" lateral to the midline. Horizontal fissure in left lung is starting from the oblique fissure in the mid axillary line horizontally to the anterior border of the lung thus dividing the left lung into three lobes as shown in Fig.1. Right lung is divided into two lobes by oblique fissure which running obliquely downwards forwards crossing the posterior border about 2" below the apex and inferior border about 3" lateral to the midline. An incomplete horizontal fissure is observed starting from the oblique fissure at the mid axillary line horizontally but did not reach the anterior border of the lung as shown in Fig. 2. 

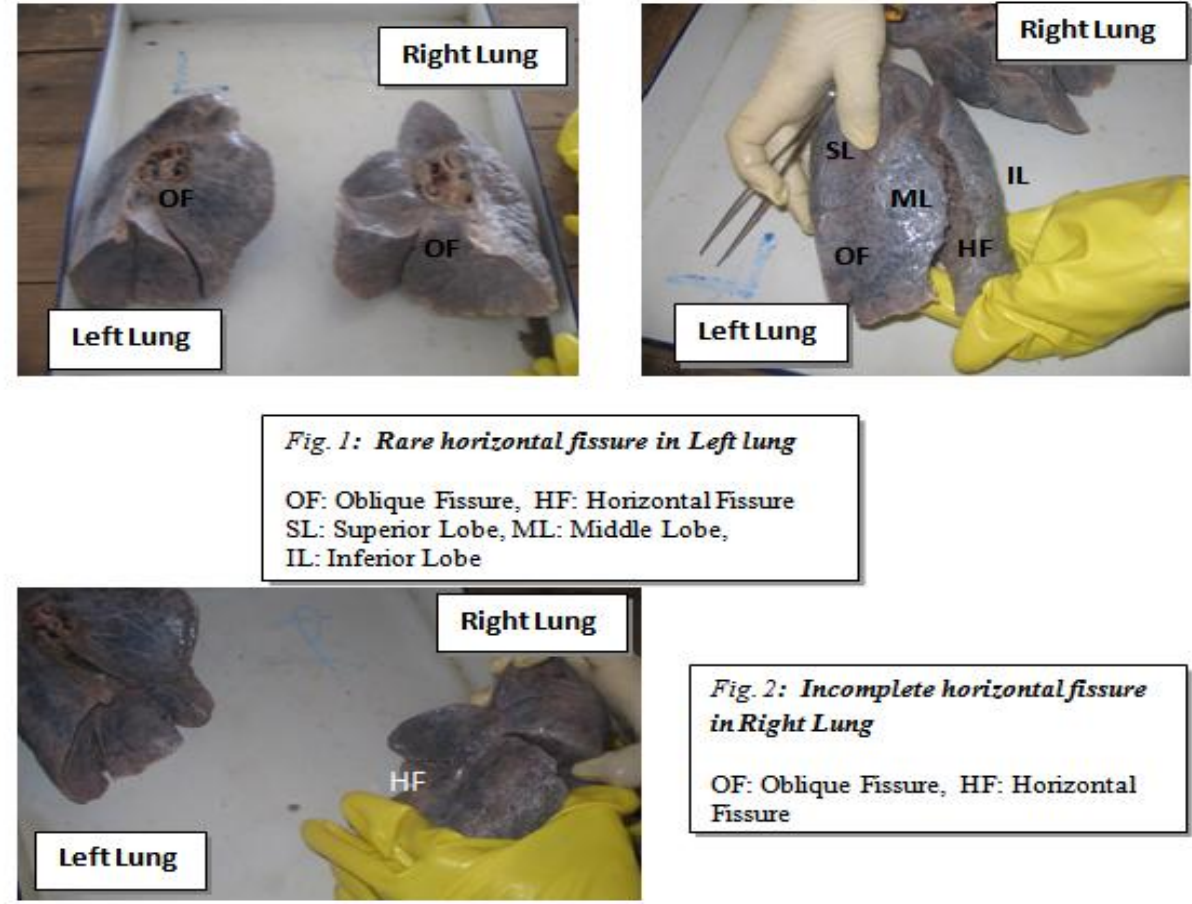

III.

DISCUSSION

As the lung grows, during the development the spaces or fissures that separate the individual broncho pulmonary segments become obliterated except at two planes i.e., oblique and horizontal fissures. Absence or incomplete fissure may be due to obliteration either completely or partially. More than half of pulmonary fissures are incomplete [3]. Medler found 17\% of incomplete horizontal fissure in Right lungs [4]. The present study also revealed a case of an incomplete horizontal fissure in the right lung. A left horizontal fissure is normal variant found in $10 \%$ of individuals [2]. Craig and Walker have proposed a fissural classification based on both the degree of completeness of the fissures and the location of the pulmonary artery at the base of the oblique fissure. Four stages have been described as:

- Grade I - complete fissure with entirely separate lobes;

- Grade II - complete visceral cleft but parenchymal fusion at the base of the fissure;

- Grade III - visceral cleft evident for a part of the fissure; and

- Grade IV - complete fusion of lobes with no evident fissural line [5].

The present case represents the Grade I type i.e., complete fissure with entirely separate lobes in Left lung and Grade III type in Right lung. According to Tarver RD, incomplete fissures may alter the usual pattern of collapse seen in patients with endobronchial legion and may also give rise to a typical appearance of pleural effusion. Incomplete fissure alter the spread of infection to the adjacent lobes [6].

\section{CONCLUSION}

Anatomical knowledge of anomalous fissures and lobes may be of more value to Surgeons performing Lobectomies. Not only to the Surgeons, it is also important to Radiologists who are interpreting the X-rays and CTs. Identification of lobar fissures in CT images is very difficult even for experienced Surgeons because of its variable shape and appearance, further the fissure thickness is observed to be approximately $1.2 \mathrm{~mm}$ in CT images.

\section{REFERENCES}

[1] Romanes GJ., Cunningham's Manual of Practical Anatomy Vol-II Thorax and abdomen $15^{\text {th }}$ Edition 2003 Oxford University Press

[2] Vishram Singh, Anatomy of upper limb and thorax Vol-III 2009 Reed Elsevier India Pvt Limited, New Delhi.

[3] Larsen WJ. Human Embryology. New York: Churchill Livingstone; 1993: 111-30.Churchill Livingstone; 1993: 111-30.

[4] Medlar EM. Variations in interlobar fissures. AJR 1947; 57: 723-25.

[5] Craig SR, Walker WS. A proposed anatomical classification of the pulmonary fissures. J R CollSurg (Edin) 1997; $42: 233-34$.

[6] Tarver RD. How common are incomplete pulmonary fissures, and what is their clinical significance? AJR 1995; 164: 761. 